\title{
Patterns of Intracranial Glioblastoma Recurrence After Aggressive Surgical Resection and Adjuvant Management: Retrospective Analysis of 43 Cases
}

\author{
Yoshiyuki KONISHI, ${ }^{1}$ Yoshihiro MURAGAKI, ${ }^{1,2}$ Hiroshi ISEKI, ${ }^{1,2}$ \\ Norio MITSUHASHI, ${ }^{3}$ and Yoshikazu OKADA ${ }^{2}$
}

\begin{abstract}
${ }^{1}$ Faculty of Advanced Techno-Surgery, Institute of Advanced Biomedical Engineering and Science, and Departments of ${ }^{2}$ Neurosurgery and ${ }^{3}$ Radiation Oncology,

Tokyo Women's Medical University, Tokyo
\end{abstract}

\begin{abstract}
The present retrospective study evaluated the recurrence patterns after aggressive surgical removal of intracranial glioblastomas in 43 consecutive adult patients. The resection rate of the enhanced lesion on magnetic resonance imaging was $100 \%$ and $95-99 \%$ in 22 and 21 cases, respectively. All patients received postoperative fractionated radiotherapy (60 Gy in 30 fractions) with additional chemotherapy (25 cases) or vaccine therapy (18 cases). During follow-up (median 17 months), tumor recurrence was identified in 33 patients, most frequently regional within the wall of the resection cavity (20 cases). No clinical factor differed significantly between the groups of patients with regional or marginal tumor progression $(N=22)$ and patients with distant or multiple recurrences $(N=8)$. Progression-free survival did not differ significantly between these two groups $(p=0.27)$. However, overall survival was significantly longer $(p=0.04)$ in patients with regional or marginal tumor progression, and constituted $90 \%$ and $54 \%$ at 1 and 2 years after surgery, respectively, compared to $75 \%$ and $0 \%$ in patients with distant or multiple recurrences. Aggressive surgical resection and adjuvant management of intracranial glioblastoma may change its recurrence pattern. Tumor progression appears in the wall of the resection cavity or within $2 \mathrm{~cm}$ from its margin in approximately half of patients.
\end{abstract}

Key words: glioblastoma, gross total resection, progression, recurrence, survival

\section{Introduction}

Glioblastoma is the most common primary brain tumor in adults and carries an extremely grim prognosis. Management usually includes surgical resection followed by postoperative fractionated radiotherapy (FRT) as well as concomitant and adjuvant chemotherapy. Nevertheless, the incidences of recurrence, regrowth, and dissemination of the tumor are very high due to the well-known infiltrative extension far beyond the boundaries of the localized lesion identifiable with neuroimaging. ${ }^{4,20,33,37,48)}$ The progression of glioblastoma after treatment in up to $97 \%$ of cases occurs either from the bulk of the mass or within $20 \mathrm{~mm}$ from the border of its enhanced part identifiable on $\mathrm{T}_{1}$-weighted magnetic resonance (MR) imaging, and the presence of such local recurrence may be associated with impaired

Received November 28, 2011; Accepted February 27, 2012 prognosis. . $^{2,3,12,13,23,25,32,34,35,43,44,54)}$ Therefore, various methods for improvement of tumor control at the time of both initial and salvage treatment have been proposed, such as inclusion of the marginal brain tissue in the high dose area during FRT, 4,17,20,26,31-33, $35,49,50$ ) additional dose boost with stereotactic radiosurgery, ${ }^{14,18,41)}$ brachytherapy, ${ }^{10,36,43)}$ implantation of Gliadel wafers (Guilford Pharmaceuticals Inc., Baltimore, Maryland, USA), ${ }^{53)}$ or various types of intralesional immunotherapy..$^{7,42)}$

The majority of studies on progression of intracranial gliomas after initial treatment have included many cases with incomplete surgical tumor removal. Contemporary advances in neurosurgical technique and introduction of modern intraoperative technologies now permit attain gross total resection of the brain tumor in many cases. ${ }^{16,19,24,28,30,39,45)}$ Surgical treatment in the vast majority of gliomas could not be considered as curative, but more complete removal of the localized part of the neoplasm may change the dynamics of further growth and 
related prognosis. ${ }^{11,31)}$

The present retrospective analysis tried to evaluate the recurrence patterns of intracranial glioblastomas after aggressive surgery.

\section{Materials and Methods}

This retrospective study was initiated in September 2009. There were two initial selection criteria: surgery for newly diagnosed glioma performed in the intelligent operating theater of Tokyo Women's Medical University with the use of intraoperative MR (iMR) imaging; and final histopathological diagnosis of glioblastoma. Retrospective backward selection of cases from the constantly maintained computer database was started from June 2008 to allow a minimum of 12-month follow up after completion of postoperative FRT in surviving patients. Case selection was limited to the beginning of 2004, since the initial period after installation of iMR imaging in our clinic (2000) was completed by this time, significant improvement of the intraoperative image quality had succeeded, and the surgical algorithm of glioma treatment in this facility was fully established. ${ }^{16,27,28,30)}$ All selected cases were checked for resection rate. The established cut-off level of $95 \%$ or greater tumor removal was chosen, because this value corresponds to the grading of resection of malignant gliomas used by The Committee of Brain Tumor Registry of Japan.5)

A total of 65 consecutive patients underwent craniotomy and removal of the newly diagnosed intracranial glioblastoma in the intelligent operating theater of the Tokyo Women's Medical University from January 2004 to June 2008. Resection of $95 \%$ or greater was attained in 47 patients. Four patients from this cohort were excluded from further analysis due to omission of postoperative FRT. The remaining 43 patients were included in the present study. The 29 men and 14 women were aged from 18 to 79 years (median 43 years). Eighteen patients were less than 50 years old. Karnofsky performance scale (KPS) score before surgery was $100-80$ in 31 patients, 70-60 in 6 , and 50 or less in 6 . The tumor was predominantly located within the frontal (19 cases), temporal (12 cases), parietal (7 cases), and occipital ( 3 cases) lobes. Other locations were encountered in only 2 patients. The left hemisphere was affected slightly more often than right ( 23 vs. 20 cases). According to recursive partitioning analysis classification $^{6)} 12$ patients had class III, 21 had class IV, and 10 had class V.

Tumor removal was performed according to our concept of information-guided surgery ${ }^{17,28,30)}$ with the use of iMR imaging, updated neuronavigation, comprehensive neurophysiological monitoring, neurochemical monitoring with 5-aminolevulinic acid (5-ALA), and histopathological monitoring with multiple microscopic investigations of the resected tissue using frozen sections. Awake craniotomy and/or intraoperative cortical and subcortical brain mapping were performed if indicated. The main goal of surgery was defined as maximum possible removal of the contrast-enhanced area identified on preoperative $\mathrm{T}_{1}$-weighted $\mathrm{MR}$ imaging without the risk of postoperative major permanent neurological morbidity. The final histopathological diagnosis of glioblastoma was established according to the current World Health Organization criteria ${ }^{21)}$ using paraffinembedded tissue sections stained with hematoxylin and eosin and appropriate antibodies for immunohistochemistry.

Evaluation of the resection rate was based on visual side-by-side comparison of the preoperative and postoperative MR images obtained within 3 days after the surgery, using a $1.5 \mathrm{~T}$ clinical scanner (ExcellArt; Toshiba Medical Systems, Tokyo). Any contrast-enhanced area on $\mathrm{T}_{1}$-weighted images was considered to be residual tumor. ${ }^{8)}$ In the analyzed cohort, the resection rate was $100 \%$ in 22 patients, and between $95 \%$ and $99 \%$ in the other 21 patients.

All patients underwent postoperative FRT, which was initiated within 2 to 3 weeks after surgical removal of the tumor. The treatment protocol was based on the three-dimensional planning system. The total dose was $60 \mathrm{~Gy}$ delivered in 30 fractions (2 Gy per fraction) in all cases. During the initial 25 fractions (up to $50 \mathrm{~Gy}$ of irradiation), the clinical target volume (CTV) was defined as the hyperintense area on $\mathrm{T}_{2}$-weighted MR images and the $15 \mathrm{~mm}$ marginal area of the adjacent cerebral tissue. From 26 to 30 fractions (from 52 to $60 \mathrm{~Gy}$ of irradiation), the CTV was reduced to the resection cavity and the 15 $\mathrm{mm}$ marginal area of the adjacent cerebral tissue. Any contrast-enhanced area on $\mathrm{T}_{1}$-weighted MR images was always included in the irradiation field. Concomitant and adjuvant chemotherapy was administered in 25 patients according to the standard protocols for nimustine (ACNU) ${ }^{40,48)}$ (9 cases) or temozolomide ${ }^{46,47)}$ (16 cases). Chemotherapy was omitted in 18 patients, but treatment with autologous formalin-fixed tumor vaccine (AFTV) concomitant with FRT was performed. ${ }^{29)}$

Follow-up evaluations were performed by the attending neurosurgeon, starting 2 weeks after completion of FRT, and scheduled every 2-3 months thereafter. Additional examinations were done if required by the clinical condition of the patient. The regular investigations included physical testing with evaluation of KPS score and determination of the 
Medical Research Council neurological functional grade, blood and urinary tests, and brain MR imaging with contrast medium. Other investigations were not performed unless were clinically indicated. The length of follow up varied from 3 to 71 months (median 17 months).

The diagnosis of tumor recurrence was based on the joint opinions of the neurosurgeon and neuroradiologist, and was defined as appearance of new contrast-enhanced lesion(s) on $\mathrm{T}_{1}$-weighted MR images, or $25 \%$ or more increase of the volume of the previous enhanced lesion(s). Patterns of recurrence were considered as regional (in the wall of the resection cavity), marginal (within $20 \mathrm{~mm}$ from the margin of the resection cavity), distant (more than 20 $\mathrm{mm}$ from the margin of the resection cavity), multiple (several recurrences in various brain areas), and subarachnoid dissemination (Fig. 1). At the time of tumor recurrence the patients usually underwent salvage treatment, which included re-resection of the tumor, stereotactic radiosurgery, chemotherapy, vaccine therapy, or various combinations.

Clinical factors in the defined groups of patients were compared with the chi-square test or MannWhitney test. Overall (OS) and progression-free survival (PFS) were evaluated from the day of surgery and were compared with the log-rank test after construction of the Kaplan-Meier curves.
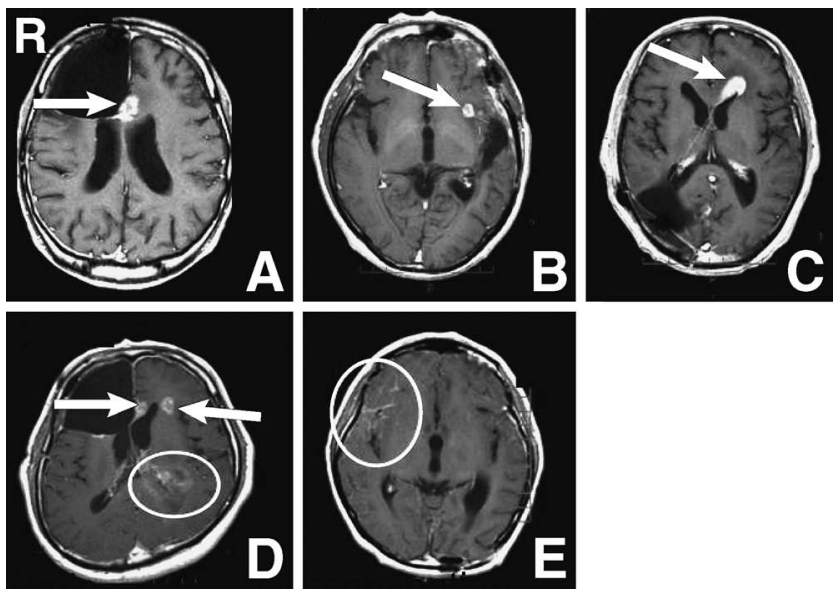

Fig. $1 T_{1}$-weighred magnetic resonance images with contrast medium illustrating the patterns of glioblastoma recurrence (arrows and circles) after aggressive surgery and adjuvant management. A: regional, in the wall of the resection cavity; B: marginal, within $20 \mathrm{~mm}$ from the margin of the resection cavity; C: distant, more than $20 \mathrm{~mm}$ from the margin of the resection cavity; $D$ : multiple, several recurrences in various brain areas; and E: subarachnoid dissemination.

\section{Results}

Tumor recurrence was observed during the followup period in 33 of 43 patients. Incidences of various recurrence patterns are presented in Table 1. Overall tumor progression within the wall of the resection cavity or within $20 \mathrm{~mm}$ from the margin accounted for $51 \%$ of cases. Subarachnoid dissemination was evident in 5 patients and was isolated pattern of recurrence in 3 of them. It was identified in 3 of 25 cases when the cerebral ventricle was opened during surgery, and in 2 of 18 cases when this was not done $(p=0.78)$. Spinal dissemination was evident in 1 patient, and no case of glioblastoma metastasis outside the central nervous system was identified.

PFS did not differ significantly between patients with regional or marginal progression of glioblastoma (22 cases) and patients with distant or multiple recurrences (8 cases), as shown in Fig. 2. Comparison of the investigated clinical factors did not differ

Table 1 Incidence of various recurrence patterns after aggressive surgery and adjuvant management of intracranial glioblastoma

\begin{tabular}{lc}
\hline \multicolumn{1}{c}{ Recurrence pattern } & No. of cases* \\
\hline Regional (in the wall of the resection cavity) & $20(46.5 \%)$ \\
$\begin{array}{l}\text { Marginal (within } 20 \mathrm{~mm} \text { from the margin of the } \\
\text { resection cavity) }\end{array}$ & $2(4.7 \%)$ \\
$\begin{array}{l}\text { Distant (more than } 20 \mathrm{~mm} \text { from the margin of the } \\
\text { resection cavity) }\end{array}$ & $4(9.3 \%)$ \\
$\begin{array}{l}\text { Multiple (several recurrences in various brain areas) } \\
\text { Subarachnoid dissemination }\end{array}$ & $4(9.3 \%)$ \\
\hline
\end{tabular}

*In 10 cases, recurrence of the tumor was not observed during follow-up period.

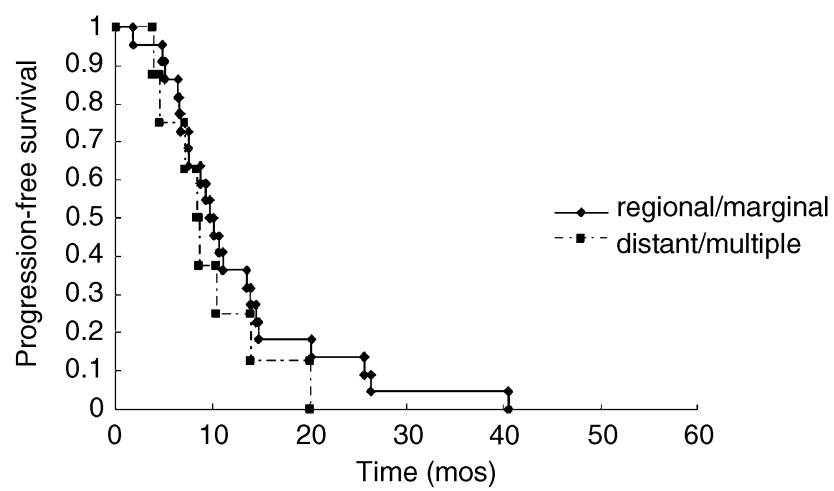

Fig. 2 Comparison of progression-free survival from the time of surgery in patients with different recurrence patterns of intracranial glioblastoma. There is no significant difference ( $p=0.27$ ). 
Table 2 Comparison of clinical factors and outcome variables in patients with different recurrence patterns of intracranial glioblastoma

\begin{tabular}{|c|c|c|c|}
\hline $\begin{array}{l}\text { Clinical factors } \\
\text { and outcome } \\
\text { variables }\end{array}$ & $\begin{array}{l}\text { Patients with } \\
\text { regional or } \\
\text { marginal } \\
\text { progression } \\
(\mathrm{N}=22)\end{array}$ & $\begin{array}{l}\text { Patients with } \\
\text { distant or } \\
\text { multiple } \\
\text { recurrences } \\
(\mathrm{N}=8)\end{array}$ & $\mathrm{p}$ Value \\
\hline \multicolumn{3}{|l|}{ Sex } & $0.35^{*}$ \\
\hline men & 15 & 5 & \\
\hline women & 7 & 3 & \\
\hline \multicolumn{3}{|l|}{ Age } & $0.70^{*}$ \\
\hline$<50$ yrs & 10 & 3 & \\
\hline$\geq 50$ yrs & 12 & 5 & \\
\hline Median age (range), yrs & $52(18-68)$ & $56(36-79)$ & $0.16^{* *}$ \\
\hline \multicolumn{3}{|c|}{ KPS score } & $0.21^{*}$ \\
\hline $80-100$ & 18 & 4 & \\
\hline $60-70$ & 1 & 2 & \\
\hline$\leq 50$ & 3 & 2 & \\
\hline \multicolumn{3}{|l|}{ Tumor location } & $0.24^{*}$ \\
\hline frontal & 11 & 2 & \\
\hline temporal & 6 & 4 & \\
\hline parietal & 2 & 2 & \\
\hline occipital & 1 & 0 & \\
\hline other & 2 & 0 & \\
\hline \multicolumn{3}{|l|}{ Tumor side } & $0.23^{*}$ \\
\hline left & 12 & 2 & \\
\hline right & 10 & 6 & \\
\hline \multicolumn{3}{|l|}{ RPA class } & $0.29^{*}$ \\
\hline III & 7 & 2 & \\
\hline IV & 11 & 2 & \\
\hline V & 4 & 4 & \\
\hline \multicolumn{3}{|l|}{ Resection rate } & $0.41^{*}$ \\
\hline $100 \%$ & 10 & 5 & \\
\hline $95-99 \%$ & 12 & 3 & \\
\hline \multicolumn{3}{|l|}{ Adjuvant treatment } & $0.70^{*}$ \\
\hline $\begin{array}{l}\text { chemotherapy (ACNU } \\
\text { or TMZ) }\end{array}$ & 10 & 3 & \\
\hline vaccine therapy & 12 & 5 & \\
\hline \multicolumn{4}{|l|}{ Salvage treatment } \\
\hline any & 14 & 6 & $0.56^{*}$ \\
\hline re-resection & 8 & 0 & $0.05^{*}$ \\
\hline $\begin{array}{l}\text { gamma knife } \\
\text { radiosurgery }\end{array}$ & 0 & 1 & $0.09^{*}$ \\
\hline chemotherapy (TMZ) & 13 & 6 & $0.42^{*}$ \\
\hline vaccine therapy & 1 & 0 & $0.54^{*}$ \\
\hline \multicolumn{3}{|l|}{ Outcome } & $0.29^{*}$ \\
\hline dead & 15 & 7 & \\
\hline alive & 7 & 1 & \\
\hline \multicolumn{3}{|l|}{ Overall survival } & $0.04^{* * *}$ \\
\hline median (range), mos & $27(3-57)$ & $14(6-23)$ & \\
\hline $\begin{array}{l}\text { actuarial 1-yr rate } \\
(95 \% \mathrm{CI})\end{array}$ & $90 \%(78-100 \%)$ & $75 \%(45-100 \%)$ & \\
\hline $\begin{array}{l}\text { actuarial 2-yr rate } \\
\qquad(95 \% \mathrm{CI})\end{array}$ & $54 \%(32-76 \%)$ & $0 \%$ & \\
\hline \multicolumn{3}{|c|}{ Progression-free survival } & $0.27^{* * *}$ \\
\hline median (range), mos & $10(2-41)$ & $8(4-20)$ & \\
\hline $\begin{array}{l}\text { actuarial 1-yr rate } \\
(95 \% \mathrm{CI})\end{array}$ & $36 \%(16-56 \%)$ & $25 \%(0-55 \%)$ & \\
\hline $\begin{array}{l}\text { actuarial 2-yr rate } \\
\quad(95 \% \mathrm{CI})\end{array}$ & $14 \%(0-28 \%)$ & $0 \%$ & \\
\hline
\end{tabular}

According to ${ }^{*}$ chi-square test, ${ }^{* *}$ Mann-Whitney test, and $*^{* *}$ log-rank test. ACNU: nimustine, CI: confidence interval, KPS: Karnofsky performance status, RPA: recursive partitioning analysis, TMZ: temozolomide. significantly between the two defined groups (Table 2 ). No correlation between tumor location and recurrence pattern was found, but the recurrent tumor affected genu of the corpus callosum in all 4 patients with glioblastoma initially located in the prefrontal region (Fig. 3). In contrast, no neoplasm located in the parietal and/or occipital lobes recurred in the splenium of the corpus callosum.

Salvage treatment was performed in 14 of 22 patients with regional or marginal tumor progression and in 6 of 8 patients with distant or multiple recurrences $(\mathrm{p}=0.56)$. However, re-craniotomy and additional lesion resection were done only in 8 cases of the former group ( $p=0.05)$. Histopathological investigation revealed pure recurrence of the neoplasm in 6 cases, and intermixture with radiation necrosis in 2. Patients with regional or marginal progression of glioblastoma, who underwent reresection of the neoplasm, had a mild tendency to better OS (median 13 vs. 10 months after diagnosis of recurrence), but the difference did not reach statistical significance (Fig. 4).

At the time of data analysis, 18 patients remained alive, whereas 25 had died, all of the intracranial tumor. OS was longer in patients with regional or marginal progression of glioblastoma compared to patients with distant or multiple recurrences $(\mathrm{p}=$ 0.04), as shown in Fig. 5.

\section{Discussion}

The conventional objectives of resective surgery for malignant glioma include relief of compression of the tumor bulk on the surrounding brain (important for neurological improvement), reduction of the volume of the neoplasm (increases the efficacy of adjuvant postoperative treatment), and establishment of the precise histopathological diagnosis (required for choice of the appropriate therapy, optimal follow up, and prediction of prognosis). ${ }^{1)}$ Additionally, extensive removal of the neoplasm may positively influence the survival. While the latter has not been formally proved to date, ${ }^{38)}$ there is a growing agreement that total resection of the lesion is associated with better long-term outcome. Adjustment for biases of age and eloquent area location in the dataset of randomized study on use of neurochemical navigation with 5-ALA during resection of glioblastoma found that median OS after complete removal of the enhanced lesion was significantly longer compared to cases with incomplete resection (17 months vs. 12 months). ${ }^{45}$ In concordance, the report on European Organisation for Research and Treatment of Cancer randomized trial of combined chemotherapy for anaplastic gliomas showed the OS 


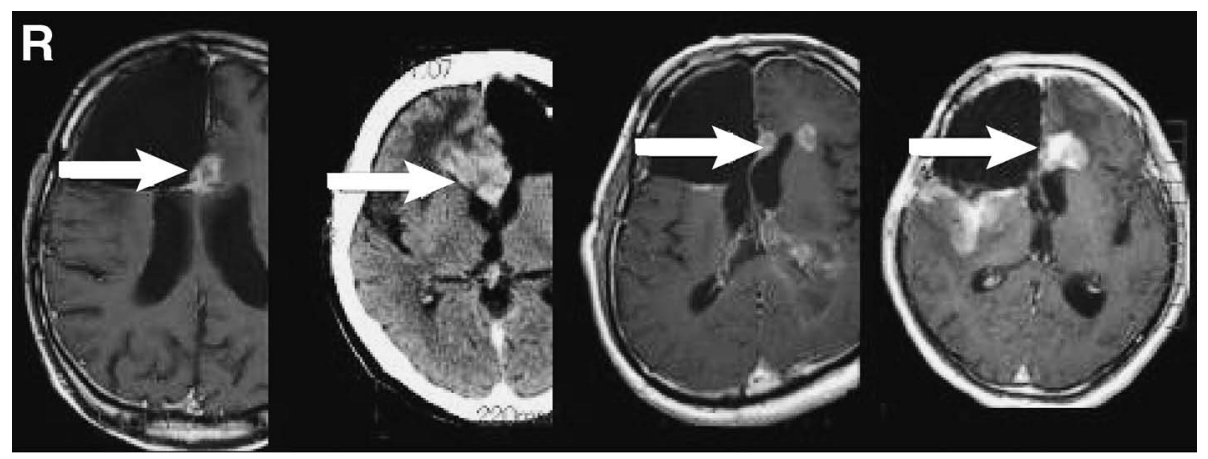

Fig. 3 Follow-up images in 4 patients with glioblastoma initially located in the prefrontal region showing the recurrent tumor affected the genu of the corpus callosum (arrows).

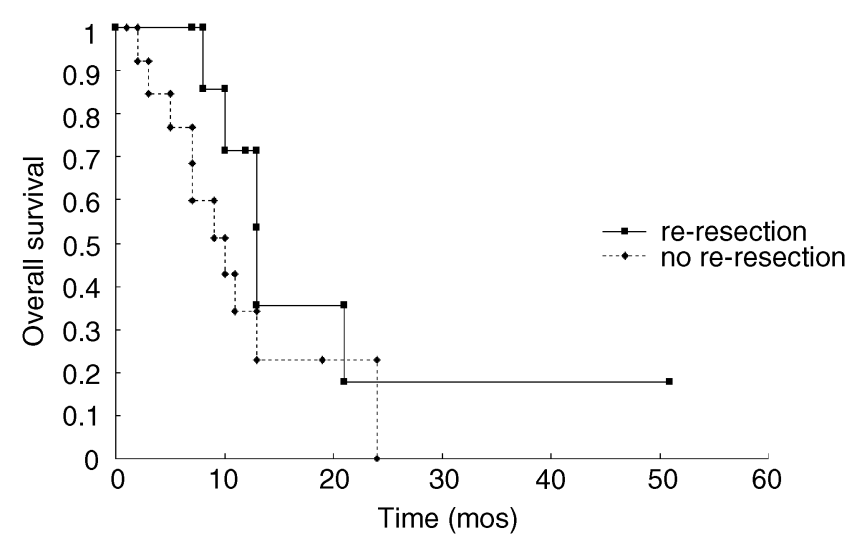

Fig. 4 Comparison of the overall survival from the time of regional or marginal tumor progression relative to re-resection. There is no significant difference $(p=$ 0.20).

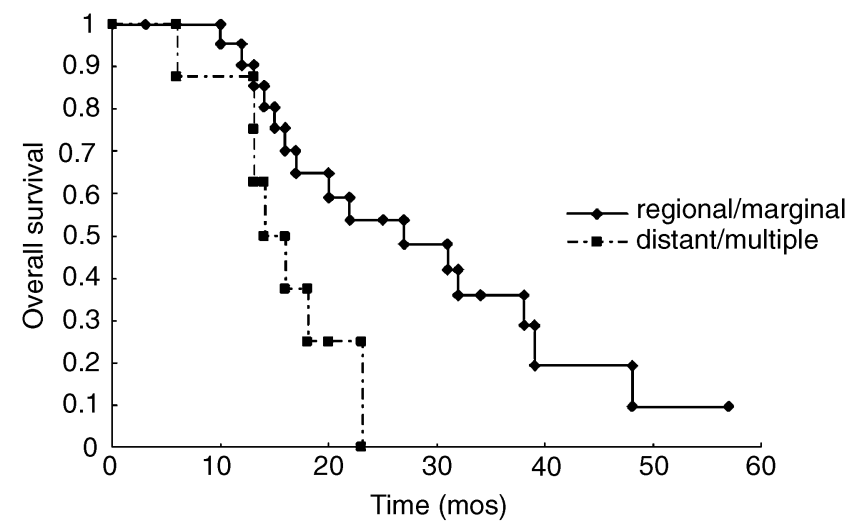

Fig. 5 Comparison of the overall survival from the time of surgery in patients with different recurrence patterns of intracranial glioblastoma. There is a significant difference $(p=0.04)$. was better after complete tumor removal compared to partial removal or biopsy. ${ }^{51)}$ Resection of $98 \%$ or more of glioblastoma is associated with significant improvement of the long-term outcome, ${ }^{19)}$ whereas the same trend was recently revealed even at $78 \%$ resection rate. ${ }^{39)}$ Concordant results were reported by The Committee of Brain Tumor Registry of Japan: analysis of 5,328 cases of glioblastoma showed that more than $95 \%$ tumor removal is associated with survival advantage, but such resection rate was attained in only $31.4 \%$ of cases. ${ }^{5)}$ In our series, $95 \%$ and more resection was achieved in 47 of 65 consecutive patients $(72 \%)$. After aggressive surgery and adjuvant management $23 \%$ of patients remained free of tumor progression within the median follow-up period of 17 months. Such beneficial results may reflect the advantages of our treatment concept of information-guided surgery for brain tumors based on the constant use of advanced intraoperative technologies. ${ }^{17,28,30)}$

Our surgical strategy for information-guided management of intracranial gliomas with the use of iMR imaging has been described in detail elsewhere. ${ }^{27,28,30)}$ It is based on the integration of various intraoperative anatomical, functional, and histological data to attain maximal surgical resection of the tumor with minimal risk of postoperative neurological morbidity. It should be specifically emphasized that complete removal is highly desirable, but is not the ultimate goal of surgery for glioma. In our practice, the procedure is usually directed to the maximal possible resection of the enhanced area in cases of high-grade glioma, which might be radiologically total as well as subtotal, leaving the residual lesion within the functioning eloquent brain structures identified with neurophysiological monitoring and/or brain mapping. ${ }^{27,28,30)}$

In the majority of reported series, local progression of intracranial glioblastoma after initial 
Table 3 Recurrence rates of intracranial glioblastoma after treatment

\begin{tabular}{|c|c|c|c|c|c|}
\hline Author (Year) & $\begin{array}{l}\text { No. of } \\
\text { analyzed } \\
\text { cases }\end{array}$ & Cohort characterization & $\begin{array}{l}\text { Length of } \\
\text { follow-up } \\
\text { (mos) }\end{array}$ & $\begin{array}{l}\text { Total } \\
\text { recurrence } \\
\text { rate }\end{array}$ & $\begin{array}{l}\text { Local } \\
\text { recurrence } \\
\text { rate }\end{array}$ \\
\hline $\begin{array}{l}\text { Hochberg and } \\
\text { Pruitt (1980) }\end{array}$ & 42 & $\begin{array}{l}\text { CT-based delineation of the tumor recurrence after } \\
\text { irradiation and/or chemotherapy (CCNU); } \\
\text { Anaplastic astrocytomas might be included }\end{array}$ & ND & ND & $80 \%$ \\
\hline$\underset{(1989)^{32)}}{\text { Nagashima et al. }}$ & 48 & $\begin{array}{l}\text { Comparison of } 3 \text { FRT techniques with irradiation dose } \\
>45 \mathrm{~Gy} \text { in each case: WBRT, generous local } \\
\text { irradiation (complete coverage of the area of } \\
\text { hypodensity on CT), and restricted local irradiation } \\
\text { (within } 2 \mathrm{~cm} \text { of the CT-defined tumor margin) }\end{array}$ & ND & $100 \%$ & $85 \%$ \\
\hline $\begin{array}{l}\text { Sneed et al. } \\
(1994)^{43)}\end{array}$ & 25 & $\begin{array}{l}\text { Surgery, FRT (59.4-60 Gy) with concomitant oral } \\
\text { hydroxyurea followed by brachytherapy with } \\
\text { high-activity ( } 50 \mathrm{~Gy} \text { ) iodine-125 sources and } 6 \text { cycles } \\
\text { of chemotherapy (procarbazine, lomustine, and } \\
\text { vincristine) }\end{array}$ & ND & $88 \%$ & $68 \%$ \\
\hline $\begin{array}{l}\text { Nakagawa et al. } \\
(1998)^{33)}\end{array}$ & 38 & $\begin{array}{l}\text { Surgical resection or biopsy in all cases (gross total } \\
\text { resection } 8 \% \text { ), followed by FRT (60-90 Gy in } 20 \\
\text { cases and } \geq 90 \text { Gy in 16) concurrent with } \\
\text { chemotherapy (ACNU and vincristine) }\end{array}$ & ND & $84 \%$ & $53 \%$ \\
\hline $\begin{array}{l}\text { Oppitz et al. } \\
\left.(1999)^{35}\right)\end{array}$ & 34 & $\begin{array}{l}\text { CT-based analysis of recurrence after FRT (range of } \\
\text { total doses } 45-68 \mathrm{~Gy} \text {, median } 60 \mathrm{~Gy} \text { ) }\end{array}$ & ND & $100 \% *$ & $97 \%$ \\
\hline $\begin{array}{l}\text { Wick et al. } \\
\qquad(2008)^{54)}\end{array}$ & 63 & $\begin{array}{l}\text { Comparison of recurrence patterns in only radiotherapy } \\
\text { group ( } 33 \text { cases) and TMZ-based chemoradiotherapy } \\
\text { group (30 cases); } \\
\text { "Debulking surgery" was done in } 37 \text { patients }\end{array}$ & ND & $100 \%{ }^{*}$ & $80 \%$ \\
\hline $\begin{array}{l}\text { Brandes et al. } \\
\quad(2009)^{2)}\end{array}$ & 95 & $\begin{array}{l}\text { Total or subtotal surgical resection followed by } \\
\text { TMZ-based chemoradiotherapy (irradiation dose } 60 \\
\text { Gy) }\end{array}$ & $\begin{array}{l}\text { median } 18.9 \\
\text { range } 6.6-44.8\end{array}$ & $83 \%$ & $72 \%$ \\
\hline $\begin{array}{l}\text { Milano et al. } \\
\qquad(2010)^{25)}\end{array}$ & 54 & $\begin{array}{l}\text { Surgical resection or biopsy (gross total resection } 31 \% \text { ), } \\
\text { followed by TMZ-based chemoradiotherapy } \\
\text { (irradiation dose } 60 \mathrm{~Gy} \text { ); } \\
\text { Additional SRS boost in } 3 \text { patients }\end{array}$ & median 17 & $72 \%$ & $67 \%$ \\
\hline $\begin{array}{l}\text { Chamberlain } \\
(2011)^{3)}\end{array}$ & 70 & $\begin{array}{l}\text { Initial treatment with FRT with concurrent and adjuvant } \\
\text { TMZ followed by bevacizumab at first recurrence }\end{array}$ & ND & $100 \% *$ & $80 \%$ \\
\hline $\begin{array}{l}\text { McDonald et al. } \\
\qquad(2011)^{23)}\end{array}$ & 62 & $\begin{array}{l}\text { Evaluation of the limited margin FRT (total dose } 60 \\
\text { Gy); } \\
\text { Gross total tumor resection in } 45 \% \text { of patients; } \\
\text { Concurrent and adjuvant chemotherapy with TMZ ( } 97 \% \\
\text { of patients) or concurrent arsenic trioxide (3\% of } \\
\text { patients) }\end{array}$ & $\begin{array}{l}\text { median } 12 ; \\
\text { maximal } 28\end{array}$ & $69 \%$ & $68 \%$ \\
\hline Oh et al. $(2011)^{34)}$ & 67 & $\begin{array}{l}\text { Evaluation of recurrence patterns after TMZ-based } \\
\text { chemoradiotherapy; } \\
\text { Tumor "resection" in } 13 \% \text { of patients }\end{array}$ & ND & $100 \% *$ & $87 \%$ \\
\hline$\underset{(2012)^{31)}}{\text { Murakami et al. }}$ & 138 & $\begin{array}{l}\text { Maximal possible tumor removal (gross total resection } \\
\text { in } 28 \% \text { of patients) followed by FRT (dose } 60 \mathrm{~Gy} \text { ) } \\
\text { with concurrent and adjuvant chemotherapy }\end{array}$ & ND & $96 \%$ & $88 \%$ \\
\hline $\begin{array}{l}\text { Pan et al. (in } \\
\text { press) }\end{array}$ & 31 & $\begin{array}{l}\text { Overall } 10 \text { patients underwent total surgical resection; } \\
\text { In } 10 \text { cases maximal tumor removal followed by FRT } \\
\text { (59.4-60.0 Gy) with concurrent and adjuvant TMZ } \\
\text { was done; } \\
12 \text { patients were treated with intracavitary } \\
\text { brachytherapy after maximal surgical debulking } \\
\text { followed by FRT ( } 45 \mathrm{~Gy} \text { ) with concurrent and } \\
\text { adjuvant TMZ; } \\
9 \text { patients had unresectable disease and underwent } \\
\text { hypofractionated radiotherapy (50-66 Gy in } 10 \\
\text { fractions) followed by adjuvant TMZ or bevacizumab }\end{array}$ & $\begin{array}{l}\text { median } 12.6 ; \\
\text { range } 3.5-50.6\end{array}$ & $100 \%$ & $52 \%$ \\
\hline Present series & 43 & $\begin{aligned} & \geq 95 \% \text { surgical resection in all cases (total resection } \\
&51 \% \text { ) followed by FRT ( } 60 \mathrm{~Gy}) \text { with chemotherapy } \\
& \text { (ACNU or TMZ) or vaccine therapy }\end{aligned}$ & $\begin{array}{l}\text { median } 17 ; \\
\text { range } 3-71\end{array}$ & $77 \%$ & $51 \%$ \\
\hline
\end{tabular}

*Series included only cases with recurrences. ACNU: nimustine, CT: computed tomography, CCNU: lomustine, FRT: fractionated radiotherapy, ND: no data, SRS: stereotactic radiosurgery, TMZ: temozolomide, WBRT: whole brain radiation therapy.

management was encountered in $67 \%$ to $97 \%$ of cases (Table 3), 2,3,12,23,25,31,32,34,35,43,54) but comparison of different studies is difficult due to differences in treatment strategy, proportion of patients with total surgical tumor removal, postoperative surveillance, length of follow-up, as well as definition and categorization of the tumor progression. Nevertheless, aggressive resection of the neoplasm may 
change its recurrence pattern. ${ }^{11,31)}$ In a recent study, regional re-growth of glioblastoma after surgery and chemoradiotherapy was noted in $100 \%$ of biopsied and $97 \%$ of partially removed lesions, but in just $62 \%$ of lesions after gross total resection. ${ }^{31}$ Moreover, in $10 \%$ of the latter cases, PFS for more than 24 months was marked, which is more or less comparable to the present results. We were able to identify two other series which demonstrated similar outcomes. High-dose FRT (from 60 to more than $90 \mathrm{~Gy}$ ) concurrent with chemotherapy (ACNU, vincristine) resulted in 53\% local recurrence rate. ${ }^{33)}$ In another series aggressive management, including total tumor removal ( $32 \%$ of cases), brachytherapy, and hypofractionated radiotherapy, resulted in 52\% local tumor progression within a median follow up of 12.6 months. ${ }^{36)}$ Based on these findings, we suggest that aggressive management with gross total resection and/or high dose irradiation may result in improvement of local control of intracranial glioblastoma.

In cases of malignant glioma infiltration of the tumor cells can be identified far beyond the localized contrast-enhanced area identifiable on MR imaging. Therefore, comprehensive evaluation of the distant spread of neoplasm is necessary in each individual case, ${ }^{36)}$ and can be possibly attained with detailed analysis of fluid-attenuated inversion recovery or $\mathrm{T}_{2}$-weighted MR images, as well as functional and metabolic information obtained with perfusionweighted, diffusion-weighted, and diffusion tensor imaging, or with ${ }^{1} \mathrm{H}-\mathrm{MR}$ spectroscopy. ${ }^{13,54)}$ Such distant tumor spread may vary from one patient to another, and aggressive local management, including surgery and irradiation, can be expected to have greater efficacy for more localized disease. Correspondingly, regional or marginal tumor progression after initial total or nearly total resection of glioblastoma followed by postoperative FRT should appear later compared to distant recurrences, which are affected only by systemic therapy. However, this was not confirmed in the present study, since PFS did not differ significantly between the two groups of patients. Previously, similar PFS was found in patients with local and distant recurrences of glioblastoma, ${ }^{34)}$ whereas some series demonstrated that time to regional tumor progression might be even shorter compared to distant failure. ${ }^{25,31,36)}$

At present, the standard management of glioblastoma includes chemotherapy with temozolomide concomitant and adjuvant to FRT. ${ }^{46,47)}$ This treatment is not complication-free, ${ }^{15)}$ which is enforcing the search for novel therapeutic options for malignant gliomas. Interest is growing in modalities based on tumor-specific immune reactions, which have potentially high benefit-to-risk ratio. Our recent prospective study on the use of AFTV concomitant with FRT for management of newly diagnosed glioblastoma showed very promising results. ${ }^{29)}$ In the present analysis, the recurrence patterns did not differ between patients, who underwent chemotherapy or vaccine therapy, so both types of adjuvant management may have comparable efficacy in control of the tumor progression after initial treatment. However, systemic therapy in general may have rather limited effect on the recurrence pattern of glioblastoma, as distant failure was noted in $18 \%$ of patients in the temozolomide-based chemoradiotherapy group, and $23 \%$ of those ones in FRT only group. ${ }^{54)}$

The present study did not identify any clinical factor associated with specific recurrence patterns of intracranial glioblastoma. However, all tumors initially located in the prefrontal region at the time of further progression invariably affect the genu of the corpus callosum. Therefore, routine inclusion of this area into the irradiation field after total or near total surgical resection of such neoplasms might be reasonable. Several previous studies found that local recurrence of glioblastoma was associated with impaired prognosis. ${ }^{2,12,25,44)}$ In particular, the median survival was $17.3,14.8$, and 26.1 months in patients with recurrence inside, at the margin, and outside the irradiation field. ${ }^{2)}$ In contrast, our 22 patients with regional or marginal progression of the tumor had significantly longer $(\mathrm{p}=0.04)$ OS compared to patients with distant or multiple recurrences. Corresponding OS rates were $90 \%$ vs. $75 \%$ at 1 year and $54 \%$ vs. $0 \%$ at 2 years after surgery. Such trends might reflect selection bias with more aggressive salvage treatment, particularly re-resection, or inclusion of some cases with pseudoprogression erroneously interpreted as local recurrence, which might result in survival advantage.

Modifications of clinical practice during the study period represent unavoidable pitfall of any retrospective investigation, but seemingly did not affect the results of the present study. On the other hand, absence of volumetric tumor assessment might lead to somewhat inaccurate estimation of the resection rate. Nevertheless, the criteria for total removal were rather strict, since any contrast-enhanced area on postoperative MR imaging obtained within 3 days after surgery was considered to be residual neoplasm. ${ }^{8)}$ In fact, visual side-by-side comparison of MR images still represents a rather common method for the evaluation of treated intracranial tumors, but is less accurate compared to more sophisticated tools. ${ }^{9)}$ According to recent recommendations of the Response Assessment in Neuro-Oncology Working 
Group, volumetric methods for postoperative evaluation of gliomas are not ultimately required at present and still considered as a field of major research. ${ }^{22,52)}$

In conclusion, aggressive surgical resection and adjuvant management of intracranial glioblastoma may change its recurrence patterns. Further tumor progression appears in the wall of the resection cavity or within $2 \mathrm{~cm}$ from its margin in approximately half of such patients. This group has a trend for longer OS compared to patients with distant or multiple recurrences.

\section{Acknowledgements}

The authors are grateful to Drs. Takashi Maruyama, Masahiko Tanaka, Masayuki Nitta, Katsuya Maebayashi, Soko Ikuta, and Mikhail Chernov (Departments of Neurosurgery and Radiation Oncology, and Faculty of Advanced Techno-Surgery, Tokyo Women `s Medical University) for help provided with data collection and analysis. This study was supported by the Japan Society for the Promotion of Science (JSPS) through the "Funding Program for World-Leading Innovative Research and Development on Science and Technology" (FIRST Program), initiated by the Council for Science and Technology Policy (CSTP). Partial support from Research Committee of Intractable Pancreatic Diseases (Principal Investigator Dr. Toru Shimosegawa) was provided by Ministry of Health, Labor and Welfare of Japan.

\section{References}

1) Albert FK, Forsting M, Sartor K, Adams HP, Kunze S: Early postoperative magnetic resonance imaging after resection of malignant glioma: Objective evaluation of residual tumor and its influence on regrowth and prognosis. Neurosurgery 34: 45-61, 1994

2) Brandes AA, Tosoni A, Franceschi E, Sotti G, Frezza G, Amista P, Morandi L, Spagnolli F, Ermani M: Recurrence pattern after temozolomide concomitant with and adjuvant to radiotherapy in newly diagnosed patients with glioblastoma: Correlation with MGMT promoter methylation status. J Clin Oncol 27: 1275-1279, 2009

3) Chamberlain MC: Radiographic patterns of relapse in glioblastoma. J Neurooncol 101: 319-323, 2011

4) Chan JL, Lee SW, Fraass BA, Normolle DP, Greenberg HS, Junck LR, Gebarski SS, Sandler HM: Survival and failure patterns of high-grade gliomas after three-dimensional conformal radiotherapy. J Clin Oncol 20: 1635-1642, 2002

5) The Committee of Brain Tumor Registry of Japan: Report of brain tumor registry of Japan (1984-2000), 12th edition. Neurol Med Chir (Tokyo) 49 Suppl: 1-101, 2009

6) Curran WJ Jr, Scott CB, Horton J, Nelson JS, Weinstein AS, Fischbach AJ, Chang CH, Rotman M, Asbell SO, Krisch RE, Nelson DF: Recursive partitioning analysis of prognostic factors in three Radiation Therapy Oncology Group malignant glioma trials. J Natl Cancer Inst 85: 704-710, 1993

7) Dillman RO, Duma CM, Ellis RA, Cornforth AN, Schiltz PM, Sharp SL, DePriest MC: Intralesional lymphokine-activated killer cells as adjuvant therapy for primary glioblastoma. J Immunother 32: 914-919, 2009

8) Ekinci G, Akpinar IN, Baltacioglu F, Erzen C, Kilic T, Elmaci I, Pamir N: Early-postoperative magnetic resonance imaging in glial tumors: prediction of tumor regrowth and recurrence. Eur J Radiol 45: 99-107, 2003

9) Erickson BJ, Wood CP, Kaufmann TJ, Patriarche JW, Mandrekar J: Optimal presentation modes for detecting brain tumor progression. AJNR Am J Neuroradiol 32: 1652-1657, 2011

10) Fabrini MG, Perrone F, De Franco L, Pasqualetti F, Grespi S, Vannozzi R, Cionini L: Perioperative highdose-rate brachytherapy in the treatment of recurrent malignant gliomas. Strahlenther Onkol 185: 524-529, 2009

11) Forsting M, Albert FK, Kunze S, Adams HP, Zenner D, Sartor K: Extirpation of glioblastomas: MR and CT follow-up of residual tumor and regrowth patterns. AJNR Am J Neuroradiol 14: 77-87, 1993

12) Hochberg FH, Pruitt A: Assumptions in the radiotherapy of glioblastoma. Neurology 30: 907-911, 1980

13) Hou LC, Veeravagu A, Hsu AR, Tse VCK: Recurrent glioblastoma multiforme: a review of natural history and management options. Neurosurg Focus 20(4): E3, 2006

14) Hsieh PC, Chandler JP, Bhangoo S, Panagiotopoulos K, Kalapurakal JA, Marymont MH, Cozzens JW, Levy RM, Salehi S: Adjuvant gamma knife stereotactic radiosurgery at the time of tumor progression potentially improves survival for patients with glioblastoma multiforme. Neurosurgery 57: 684-692, 2005

15) Ikuta S, Muragaki $Y$, Maruyama T, Ogata $H$, Iseki $H$ : [Assessment of effect and toxicity of temozolomide combined with radiation therapy for newly-diagnosed glioblastoma in Japan]. Tokyo Joshi Ika Daigaku Zasshi 79: 510-515, 2009 (Japanese)

16) Iseki H, Nakamura R, Muragaki $Y$, Suzuki $T$, Chernov M, Hori T, Takakura K: Advanced computer-aided intraoperative technologies for information-guided surgical management of gliomas: Tokyo Women's Medical University experience. Minim Invasive Neurosurg 51: 285-291, 2008

17) Iuchi T, Hatano K, Narita $Y$, Kodama T, Yamaki T, Osato K: Hypofractionated high-dose irradiation for the treatment of malignant astrocytomas using simultaneous integrated boost technique by IMRT. Int $J$ 
Radiat Oncol Biol Phys 64: 1317-1324, 2006

18) Kondziolka D, Flickinger JC, Bissonette DJ, Bozik M, Lunsford LD: Survival benefit of stereotactic radiosurgery for patients with malignant glial neoplasms. Neurosurgery 41: 776-785, 1997

19) Lacroix M, Abi-Said D, Fourney DR, Gokaslan ZL, Shi W, DeMonte F, Lang FF, McCutcheon IE, Hassenbusch SJ, Holland E, Hess K, Michael C, Miller D, Sawaya R: A multivariate analysis of 416 patients with glioblastoma multiforme: prognosis, extent of resection, and survival. J Neurosurg 95: 190-198, 2001

20) Laperriere N, Zuraw L, Cairncross G: Radiotherapy for newly diagnosed malignant glioma in adults: A systematic review. Radiother Oncol 64: 259-273, 2002

21) Louis DN, Ohgaki H, Wiestler OD, Cavenee WK (eds): WHO Classification of Tumours of the Central Nervous System. Lyon, IARC, 2007

22) Lutz K, Radbruch A, Wiestler B, Baumer P, Wick W, Bendszus M: Neuroradiological response criteria for high-grade gliomas. Clin Neuroradiol 21: 199-205, 2011

23) McDonald MW, Shu HKG, Curran WJ Jr, Crocker IR: Pattern of failure after limited margin radiotherapy and temozolomide for glioblastoma. Int J Radiat Oncol Biol Phys 79: 130-136, 2011

24) Mikuni N, Miyamoto S: Surgical treatment of glioma: extent of resection applying functional neurosurgery. Neurol Med Chir (Tokyo) 50: 720-726, 2010

25) Milano MT, Okunieff P, Donatello RS, Mohile NA, Sul J, Walter KA, Korones DN: Patterns and timing of recurrence after temozolomide-based chemoradiation for glioblastoma. Int J Radiat Oncol Biol Phys 78: 1147-1155, 2010

26) Monjazeb AM, Ayala D, Jensen C, Case LD, Bourland JD, Ellis TL, McMullen KP, Chan MD, Tatter SB, Lesser GJ, Shaw EG: A Phase I dose escalation study of hypofractionated IMRT field-in-field boost for newly diagnosed glioblastoma multiforme. Int $J$ Radiat Oncol Biol Phys 82: 743-748, 2012

27) Muragaki Y, Iseki H, Maruyama T, Kawamata T, Yamane F, Nakamura R, Kubo O, Takakura K, Hori T: Usefulness of intraoperative magnetic resonance imaging for glioma surgery. Acta Neurochir Suppl 98: $67-75,2006$

28) Muragaki Y, Iseki H, Maruyama T, Tanaka M, Shinohara C, Suzuki T, Yoshimitsu K, Ikuta S, Hayashi M, Chernov M, Hori T, Okada Y, Takakura K: Information-guided surgical management of gliomas using low-field-strength intraoperative MRI. Acta Neurochir Suppl 109: 67-72, 2011

29) Muragaki Y, Maruyama T, Iseki H, Tanaka M, Shinohara C, Takakura K, Tsuboi K, Yamamoto T, Matsumura A, Matsutani M, Karasawa K, Shimada K, Yamaguchi N, Nakazato Y, Sato K, Uemae Y, Ohno T, Okada Y, Hori T: Phase I/IIa trial of autologous formalin-fixed tumor vaccine concomitant with fractionated radiotherapy for newly diagnosed glioblastoma. J Neurosurg 115: 248-255, 2011
30) Muragaki $Y$, Maruyama $T$, Nakamura $R$, Iseki $H$, Kubo O, Takakura K, Hori T: [Information-guided surgery for glioma removal]. No Shinkei Geka Journal 15: 384-395, 2006 (Japanese)

31) Murakami R, Hirai T, Nakamura H, Furusawa M, Nakaguchi Y, Uetani H, Kitajima M, Yamashita Y: Recurrence patterns of glioblastoma treated with postoperative radiation therapy: relationship between extent of resection and progression-free interval. Jpn J Radiol 30: 193-197, 2012

32) Nagashima T, Matsutani M, Nakamura O, Tanaka Y: [Regrowth pattern of glioblastoma multiforme after radiotherapy]. Gan No Rinsho 35: 1272-1276, 1989 (Japanese)

33) Nakagawa K, Aoki Y, Fujimaki T, Tago M, Terahara A, Karasawa K, Sakata K, Sasaki Y, Matsutani M, Akanuma A: High-dose conformal radiotherapy influenced the pattern of failure but did not improve survival in glioblastoma multiforme. Int J Radiat Oncol Biol Phys 40: 1141-1149, 1998

34) Oh J, Sahgal A, Sanghera P, Tsao MN, Davey P, Lam K, Symons S, Aviv R, Perry JR: Glioblastoma: patterns of recurrence and efficacy of salvage treatments. Can J Neurol Sci 38: 621-625, 2011

35) Oppitz U, Maessen D, Zunterer H, Richter S, Flentje M: 3D-recurrence-patterns of glioblastomas after CTplanned postoperative irradiation. Radiother Oncol 53: 53-57, 1999

36) Pan H, Alksne J, Mundt AJ, Murphy KT, Cornell M, Kesari S, Lawson JD: Patterns of imaging failures in glioblastoma patients treated with chemoradiation: a retrospective study. Med Oncol Epub 2011 Nov 23

37) Paravati AJ, Heron DE, Landsittel D, Flickinger JC, Mintz A, Chen YF, Huq MS: Radiotherapy and temozolomide for newly diagnosed glioblastoma and anaplastic astrocytoma: Validation of Radiation Therapy Oncology Group-recursive partitioning analysis in the IMRT and temozolomide era. J Neurooncol 104: 339-349, 2011

38) Proescholdt MA, Macher C, Woertgen C, Brawanski A: Level of evidence in the literature concerning brain tumor resection. Clin Neurol Neurosurg 107: 95-98, 2005

39) Sanai N, Polley MY, McDermott MW, Parsa AT, Berger MS: An extent of resection threshold for newly diagnosed glioblastomas. J Neurosurg 115: 3-8, 2011

40) Shibui S: Randomized controlled trial on malignant brain tumors-activities of the Japan Clinical Oncology Group-Brain Tumor Study Group. Neurol Med Chir (Tokyo) 44: 220-221, 2004

41) Shuto $T$, Matsunaga $N$, Suinaga J, Yoshizumi T, Tuzuki S, Ootake M: [Role of gamma knife treatment for glioblastoma]. Nippon Kagaku Ryoho Gakkai Zasshi 37: 1024-1026, 2010 (Japanese)

42) Smith MM, Thompson JE, Castillo M, Cush S, Mukherji SK, Miller CH, Quattrocchi KB: MR of recurrent high-grade astrocytomas after intralesional immunotherapy. AJNR Am J Neuroradiol 17: 1065-1071, 
1996

43) Sneed PK, Gutin PH, Larson DA, Malec MK, Phillips TL, Prados MD, Scharfen CO, Weaver KA, Wara WM: Patterns of recurrence of glioblastoma multiforme after external irradiation followed by implant boost. Int J Radiat Oncol Biol Phys 29: 719-727, 1994

44) Stewart LA: Chemotherapy in adult high-grade glioma: A systematic review and meta-analysis of individual patient data from 12 randomised trials. Lancet 359: 1011-1018, 2002

45) Stummer W, Reulen HJ, Meinel T, Pichlmeier U, Schumacher W, Tonn JC, Rohde V, Oppel F, Turowski B, Woiciechowsky C, Franz K, Pietsch T: Extent of resection and survival in glioblastoma multiforme: identification of and adjustment for bias. Neurosurgery 62: 564-576, 2008

46) Stupp R, Hegi ME, Mason WP, van den Bent MJ, Taphoorn MJ, Janzer RC, Ludwin SK, Allgeier A, Fisher B, Belanger K, Hau P, Brandes AA, Gijtenbeek J, Marosi C, Vecht CJ, Mokhtari K, Wesseling P, Villa S, Eisenhauer E, Gorlia T, Weller M, Lacombe D, Cairncross JG, Mirimanoff RO: Effects of radiotherapy with concomitant and adjuvant temozolomide versus radiotherapy alone on survival in glioblastoma in a randomised phase III study: 5-year analysis of the EORTC-NCIC trial. Lancet Oncol 10: 459-466, 2009

47) Stupp R, Mason WP, van den Bent MJ, Weller M, Fisher B, Taphoorn MJ, Belanger K, Brandes AA, Marosi C, Bogdahn U, Curschmann J, Janzer RC, Ludwin SK, Gorlia T, Allgeier A, Lacombe D, Cairncross JG, Eisenhauer E, Mirimanoff RO: Radiotherapy plus concomitant and adjuvant temozolomide for glioblastoma. $N$ Engl J Med 352: 987-996, 2005

48) Takakura K, Abe H, Tanaka R, Kitamura K, Miwa T, Takeuchi K, Yamamoto S, Kageyama N, Handa H, Mogami H, Nishimoto A, Uozumi T, Matsutani M, Nomura K: Effects of ACNU and radiotherapy on malignant glioma. J Neurosurg 64: 53-57, 1986

49) Tanaka $M$, Ino $Y$, Nakagawa K, Tago $M$, Todo $T$ : High-dose conformal radiotherapy for supratentorial malignant glioma: A historical comparison. Lancet Oncol 6: 953-960, 2005
50) Tsien C, Moughan J, Michalski JM, Gilbert MR, Purdy J, Simpson J, Kressel JJ, Curran WJ, Diaz A, Mehta MP: Phase I three-dimensional conformal radiation dose escalation study in newly diagnosed glioblastoma: Radiation Therapy Oncology Group trial 98-03. Int J Radiat Oncol Biol Phys 73: 699-708, 2009

51) van den Bent MJ, Carpentier AF, Brandes AA, Sanson M, Taphoorn MJ, Bernsen HJ, Frenay M, Tijssen CC, Grisold W, Sipos L, Haaxma-Reiche H, Kros JM, van Kouwenhoven MC, Vecht CJ, Allqeier A, Lacombe D, Gorlia T: Adjuvant procarbazine, lomustine, and vincristine improves progression-free survival but not overall survival in newly diagnosed anaplastic oligodendrogliomas and oligoastrocytomas: a randomized European Organization for Research and Treatment of Cancer phase III trial. J Clin Oncol 24: 2715-2722, 2006

52) Vogelbaum MA, Jost S, Aghi MK, Heimberger AB, Sampson JH, Wen PY, Macdonald DR, Van den Bent M, Chang SM: Application of novel response/progression measures for surgically delivered therapies for gliomas: Response Assessment in Neuro-Oncology (RANO) Working Group. Neurosurgery 70: 234-244, 2012

53) Westphal M, Hilt DC, Bortey E, Delavault P, Olivares R, Warnke PC, Whittle IR, Jaaskelainen J, Ram Z: A Phase 3 trial of local chemotherapy with biodegradable carmustine (BCNU) wafers (Gliadel wafers) in patients with primary malignant glioma. Neuro Oncol 5: 79-88, 2003

54) Wick W, Stupp R, Beule AC, Bromberg J, Wick A, Ernemann U, Platten $M$, Marosi C, Mason WP, van den Bent M, Weller M, Rorden C, Karnath HO: A novel tool to analyze MRI recurrence patterns in glioblastoma. Neuro Oncol 10: 1019-1024, 2008

Address reprint requests to: Yoshihiro Muragaki, MD, PhD, Faculty of Advanced Techno-Surgery, Institute of Advanced Biomedical Engineering and Science, Tokyo Women's Medical University, 8-1 Kawadacho, Shinjuku-ku, Tokyo 162-8666, Japan. e-mail: ymuragaki@abmes.twmu.ac.jp 